\title{
Uma escola justa contra o sistema de multiplicação das desigualdades sociais
}

\section{The just school against the system of multiplication of social inequality}

\author{
Ione Ribeiro Valle ${ }^{1}$
}

\begin{abstract}
RESUMO
Tem sido unânime entre os sociólogos a ideia de que a educação ocupa um lugar estratégico na cena moderna desde meados do século XVIII, quando Condorcet a incluiu no campo dos direitos do cidadão. Se outrora ela era unicamente uma questão familiar, ficando ao abrigo de todo debate sobre a justiça, ao ser vista como um direito torna-se de interesse de todos. Espera-se, desde então, que o desenvolvimento dos sistemas escolares não apenas amplie o "capital humano" e as competências úteis à economia, mas torne os indivíduos e as sociedades melhores e mais "civilizados". No entanto, apesar do estreitamento das relações entre educação (escolar) e justiça social, o que vai se efetivar por meio da meritocracia escolar, as desigualdades fracionam-se, multiplicam-se e diversificam-se no âmbito da escola, do mundo do trabalho, das hierarquias sociais, sem que se consiga desmontar o mecanismo e a lógica que elas ocultam. É nesse quadro de reflexão crítica que se constrói a noção de justiça escolar; uma noção que pode representar um avatar das políticas para a educação, pois abrange todas as dimensões dos sistemas educacionais. Para compreendê-la foi necessário retomar dois princípios que fundam os movimentos de escolarização e os projetos de democratização da educação das sociedades modernas: a igualdade e o mérito. Eles vêm ganhado força e legitimidade nas reformas aprovadas para a educação brasileira do novo milênio. O primeiro é considerado como um dos princípios ao mesmo tempo mais evidentes e mais complexos da justiça; o segundo é incontornável na imagem de um mundo justo, no qual cada um seria recompensado unicamente em função de seu mérito, de seus esforços
\end{abstract}

${ }^{1}$ Doutora em Ciências da Educação pela Universidade René Descartes - Paris V Sorbonne. Professora do Centro de Ciências da Educação da Universidade Federal de Santa Catarina (UFSC), Brasil. Atua no Programa de Pós-Graduação em Educação. Bolsista de produtividade em pesquisa do Conselho Nacional de Desenvolvimento Científico e Tecnológico (CNPq), Brasil. E-mail: ionevalle@ced.ufsc.br 
e dos resultados destes. Nosso objetivo nesta reflexão é tentar apreender os mecanismos da escola conservadora - e reprodutora - a fim de saber em que condições a escola pode se tornar libertadora - e justa.

Palavras-chave: justiça escolar; desigualdades sociais; democratização da educação; igualdade de oportunidades; meritocracia escolar.

\begin{abstract}
The idea that education occupies a strategic place in modern life has been unanimous among sociologists since the mid-18th century when Condorcet included education in the field of citizen rights. If before this education it was solely a question for the family and sheltered from the entire debate about justice, seeing it as a right places it in everyone's interest. Since then, it is expected that the development of school systems not only expands "human capital" and the useful skills to the economy, but makes individuals and societies better and more "civilized." Nevertheless, despite the close relationship between education (the school) and social justice, which is effectuated by means of school meritocracy, inequalities are fractioned, multiplied and diversified in the realm of the school, the world of labor, and social hierarchies, without being able to disassemble the mechanism and the logic that they hide. It is in this framework of critical reflection that the notion of school justice is constructed. It is a concept that can represent an avatar of educational policies because it encompasses all of the dimensions of the educational systems. To understand it, it was necessary to review two principles at the base of the educational movements and projects for the democratization of education in modern societies: equality and merit. They are gaining strength and legitimacy in the reforms approved for Brazilian education in the new millennium. The first is considered one of the principles of justice that is simultaneously more evident and more complex. The second is unavoidable in the image of a just world, in which each individual would be compensated solely as a function of his merit, his efforts and their results. Our objective in this reflection is to try to learn the mechanisms of the conservative - and reproductive - school to understand in what conditions the school can become liberating - and just.
\end{abstract}

Keywords: school justice; social inequalities; democratization of education; equality of opportunities; school meritocracy. 
Há quem diga que todas as noites são de sonhos. Mas há também quem garanta que nem todas, somente as de verão. Mas no fundo isso não tem muita importância. O que interessa mesmo não são as noites em si, são os sonhos. Sonhos que o homem sonha sempre. Em todos os lugares, em todas as épocas do ano, dormindo ou acordado.

William Shakespeare

$(1564-1616)$

Os políticos e os administradores da educação, assim como a população em geral, nutrem uma grande confiança na educação escolar. Afinal, o saber não distancia as crenças menos fundadas e menos racionais formando indivíduos mais autônomos? Não é importante que os membros de uma mesma sociedade partilhem valores e interesses comuns? O nível de escolarização não favorece a tolerância, o civismo, a abertura ao mundo? Os saberes não são necessários ao crescimento econômico, pessoal e profissional? A maioria dos que tentaram sua chance na escola não escaparam do destino social fixado pelo nascimento?... Enfim, o conhecimento é considerado superior à ignorância, como sublinha o paradoxo socrático (470-399 a.C.): "ninguém faz o mal voluntariamente, mas por ignorância, pois a sabedoria e a virtude são inseparáveis". Nesta mesma perspectiva, Victor Hugo (1802-1885) sublinha: "aquele que abre uma porta de escola, fecha uma prisão".

Mas essa confiança vai bem mais longe quando se é persuadido de que a escola pode transformar a sociedade, tornando-a melhor, mais justa e solidária. Se outrora a educação era unicamente uma questão familiar, ficando, portanto, ao abrigo de todo debate sobre a justiça (nem o analfabetismo, nem a aprendizagem de rudimentos eram percebidos como injustos), ao ser vista como direito do cidadão ela passa à esfera pública, tornando-se de interesse do público. Como assinala Walzer (2003, p. 274), "as escolas foram quase sempre instituições de elite, dominadas por estirpe ou sangue, ou riqueza, ou sexo, ou posição hierárquica e, por sua vez, predominante nos cargos religiosos e políticos”. Espera-se, portanto, desde então, que o desenvolvimento dos sistemas escolares não apenas amplie o "capital humano" e as competências úteis à economia, mas torne os indivíduos e as sociedades melhores e mais "civilizados".

Embora tenha se tornado difícil duvidar das virtudes da expansão contínua da educação, esse voluntarismo heroico de uma escola capaz de mudar o mundo não resiste aos fatos. Sabe-se hoje, e a sociologia da educação não tem medido esforços para aprofundar a reflexão nessa direção, que as relações entre os sistemas escolares e as sociedades nas quais eles se inserem são bem mais 
complexas e bem mais incertas do que se imaginava quando se acreditava que a escola per si, de forma miraculosa, poderia transformá-las. Ora, se nenhuma escola é o "clone" de sua sociedade, não há razão para crer que as sociedades sejam, por sua vez, diretamente transformadas pelas suas políticas e práticas escolares.

Mas, apesar das geralmente drásticas revelações dos diferentes campos científicos sobre o papel da escola na multiplicação das desigualdades sociais, anunciadas por um determinismo fatalista que a vê como um simples aparelho de reprodução social ${ }^{2}$, a relação entre educação (escolar) e justiça social permanece no centro dos ideais que movem o mundo contemporâneo. Essa relação não está apenas na base do pensamento político da modernidade ${ }^{3}$, mas compõe a agenda dos projetos de modernização 4 postos em prática pelos diferentes estados-nação, de meados do século XVIII aos dias de hoje.

Tem sido unânime entre os pesquisadores a ideia de que a educação passa a ocupar um lugar estratégico na cena moderna desde a sua inclusão no campo dos direitos do cidadão. Condorcet (1743-1794) ${ }^{5}$, ao preconizar a difusão das "luzes" a todos, suscita a esperança de edificar um mundo melhor para toda a humanidade; um mundo constituído de cidadãos capazes de usar livremente o julgamento, de compreender e exercer seus direitos e de respeitar os de outrem. A conquista do direito à educação, afirma Condorcet, deve levar a perceber a "comum humanidade" e a aceitar o lugar na hierarquia das posições sociais que lhe é devido, segundo o princípio da justa apreciação do mérito de cada um.

É nesse quadro de reflexões que a igualdade e o mérito passam a figurar como princípios-chaves à organização das sociedades, e o acesso de todos à instrução torna-se bandeira de luta dos mais variados movimentos revolucioná-

${ }^{2}$ Os estudos de Pierre Bourdieu (1930-2002) têm sido situados como uma das fontes primordiais das concepções ditas reprodutivistas, em particular sua obra "A reprodução", elaborada em coautoria com Jean-Claude Passeron (1930-) e publicada na França em 1970 e no Brasil em 1975. Mas eles não são os únicos. No Brasil, trabalhos como os de Louis Althusser (1918-1990) sobre os aparelhos ideológicos do Estado (AIE), inscritos nas chamadas teorias crítico-reprodutivistas, tiveram grande impacto sobre os educadores e pesquisadores nas décadas de 1970 e 1980, tendo sido publicado em português e francês em 1970.

${ }^{3}$ Sobre o termo modernidade, ver Bauman (2001); sobre as sociologias da modernidade, ver Martuccelli (1999).

${ }^{4} \mathrm{O}$ termo modernização, ligado essencialmente a um processo global de mudança social, ganha força, sobretudo, a partir da segunda metade do século XX, estando associado ao termo desenvolvimento (econômico, político, industrial, social, educacional); um termo caro à sociologia contemporânea. Sobre a modernização, ver, sobretudo, Berman (2007).

${ }^{5}$ Marie Jean Antoine Nicolas de Caritat, filósofo e matemático francês, geralmente denominado de Nicolas de Condorcet ou somente Condorcet. Sobre o seu pensamento em relação à educação, ver sobretudo Condorcet (2008); Boto (2003). 
rios. À escola é atribuída a missão de formar indivíduos autônomos, espíritos capazes de pensar por si mesmos e de se livrar das sujeições de toda ordem que entravam sua emancipação. Para Condorcet (2008, p. 160), ao falar aos homens de direitos, comuns a todos, "no exercício dos quais toda violação da igualdade é um crime, só lhes falaremos de seus interesses mostrando-lhes seus deveres, e toda lição de política será uma lição de justiça". Segundo ele, cabe ao Estado a responsabilidade pelo combate de todas as formas de desigualdades que impedem o progresso pessoal e social e não apenas aquelas decorrentes da fortuna.

Ao analisar as retóricas políticas da educação ao longo de dois séculos, Garnier (2010) afirma que a perspectiva de Condorcet apresenta uma dimensão universal fundada na ideia de produção de uma hierarquia entre os indivíduos por meio da educação. Esta deve preparar cada um para ocupar o lugar que lhe convém e que convém à utilidade coletiva. Nesse sentido, Condorcet faz a síntese entre os movimentos de pensamento fundados no desenvolvimento do direito natural e na filosofia do contrato, desenvolvidos principalmente por Jean-Jacques Rousseau (1712-1778) e Denis Diderot (1713-1784). Neles a questão da igualdade frente à instrução aparece como direito de liberdade, estando destinada a formar cidadãos e homens livres. Enfim, parece evidente que, ao pôr a igualdade dos direitos no centro do seu projeto de sociedade, Condorcet procura fazer com que coincidam a fronteira social e a fronteira da instrução.

Como se vê, desde então, estreita-se a relação entre educação escolar e justiça social e são traçados os contornos do que se denomina hoje de meritocracia escolar ${ }^{6}$. Diferentes princípios, nem sempre convergentes, passam a ser mobilizados a fim de promover esta articulação: o direito, a igualdade, o mérito, a equidade, a solidariedade, a autonomia, a cidadania, a emancipação, a coletividade, a coesão. No entanto, são os princípios da igualdade e do mérito que vão fundar as políticas de democratização da educação ${ }^{7}$ (conceito que define fins e justifica ações administrativas e pedagógicas diversificadas), seja como princípios de direito, seja para justificar conquistas individuais e projetos governamentais, seja como modo de distribuição dos chamados bens sociais, seja, enfim, como mecanismo de alocação das funções profissionais.

Consideramos que para entender o conceito de justiça escolar, objetivo a que nos propomos neste momento, é necessário recuperar algumas reflexões que estão na base da constituição dos sistemas escolares. Por essa razão, nos debruçaremos sobre os princípios da igualdade e do mérito. Eles estão na base

${ }^{6}$ Sobre as noções de mérito, meritocracia e meritocracia escolar, ver Valle e Ruschel (2010).

${ }^{7}$ Pensar na democratização da educação supõe retomar permanentemente o conceito de democracia. A obra de Martiniello (2011) nos ajuda a problematizá-lo ao relacioná-lo à cidadania, à diversidade, à justiça social. 
dos discursos, das políticas, e vêm orientando as práticas educacionais ao longo do século XX, tendo ganhado força e legitimidade nas reformas aprovadas para a educação brasileira do novo milênio. O primeiro é considerado como um dos princípios ao mesmo tempo mais evidentes e mais complexos da justiça; o segundo é incontornável na imagem de um mundo justo, no qual cada um seria recompensado unicamente em função de seu mérito, de seus esforços e dos resultados destes.

\section{Igualdade e mérito: duas faces de uma mesma moeda}

Democracia é oportunizar a todos o mesmo ponto de partida. Quanto ao ponto de chegada, depende de cada um.

Fernando Sabino (1923-2004)

Procurando não ficar presos a perspectivas muitas vezes polêmicas, inscritas menos na ordem de uma incomensurável oposição que na ordem de uma tensão dinâmica, partimos das reflexões sobre a noção "mágica" da escola democrática que transforma dons e talentos individuais em virtudes sociais e os converte em benefícios coletivos. Parece-nos evidente que a democratização da educação, premissa que mobilizou professores, administradores, pesquisadores, pais de alunos, estudantes e a população brasileira em sua grande maioria ao longo dos anos de 1980, que fundamentou as reformas educacionais das últimas décadas e que inspirou as lutas pela igualdade do direito à educação, se confronta hoje com uma visão relativamente pessimista, fruto não de uma falta de crédito na educação escolar, mas do fracasso das políticas para a educação do país. Ao analisar as políticas educacionais francesas voltadas à democratização da frequência, Carpentier (2010, p. 52) indaga se se trata de um "mercado de tolos", pois segundo ele "é necessário também fazer com que os novos eleitos sejam bem-sucedidos".

Não se pode mais ignorar que a forma ideal da igualdade em educação, isto é, baseada no sentido matemático da igualdade perfeita entre dois elementos de um mesmo conjunto, nunca existiu nem na realidade nem nos espíritos (GARNIER, 2010, p. 7-8). Também não se pode esquecer que jamais alguém desejou criar seus filhos sem nenhuma distinção, em situação idêntica uns em relação aos outros, sentados sobre os mesmos bancos escolares, independentemente das dificuldades ou facilidades individuais, das diferenças de idade, de sexo, de local 
de moradia, de origem social, de projeto profissional, de convicção religiosa. Ora, nunca ninguém procurou receber e/ou oferecer um ensino completamente igual em termos de conteúdos, de material didático, de recursos tecnológicos, e que vislumbrasse o pleno sucesso de todos.

Isso nos leva a supor que o princípio genérico e abstrato da igualdade em educação, preconizado pelas políticas de democratização, cresce em importância somente quando as "promessas" educacionais se mostram frágeis e/ou contraditórias. Ele aparece primeiramente como crítica da sociedade desigual, depois como um princípio de direito e de distribuição de bens e de posições sociais e, por último, como um princípio de justiça (geralmente circunscrito ao campo jurídico), mas nunca se manifesta na defesa de uma igualdade plena, de uma igualdade sem adjetivos.

Embora, em termos legais, a igualdade do direito à educação seja chave na consolidação dos projetos de democratização, ela nunca garantiu que, em nível igual de talento, motivação e competência, todos tenham as mesmas perspectivas de sucesso, independentemente do meio social, da educação familiar e dos processos de socialização que marcam, de forma distinta, a trajetória de cada um. Além disso, nas sociedades onde as desigualdades são profundas, tal como a brasileira, o sonho da igualdade está longe de se tornar realidade. Ele suporia não apenas a mobilidade e a ascensão social, mas deveria permitir que cada um pudesse frutificar seus dons, por meio da expansão do acesso aos "bens sociais primários", da conciliação entre "universalidade e diversidade", da promoção de uma "moral mínima", eliminando assim todas as diferenças que impedem a manifestação dos méritos individuais. Em síntese, e radicalizando, ela demandaria a transformação do sistema social e econômico vigente...

Segundo Walzer (2003, p. 271), “a justiça não se relaciona só com os resultados, mas também com a vivência da educação". Seria de se esperar que uma política da igualdade garantisse os recursos necessários, de maneira que as conquistas alcançadas correspondam unicamente ao esforço pessoal e não às circunstâncias existenciais dos indivíduos. Para ele, esse princípio tem um "antes" e um "depois": antes de ingressar na competição "todos os ponteiros devem ser zerados", o que supõe uma forte intervenção social, mas uma vez inserido na competição, cada um deve assumir inteiramente a responsabilidade por suas realizações. Enfim, segundo esta perspectiva, a caixa preta da escola deve receber indivíduos iguais, em tese, e fazê-los partir desiguais.

Da mesma maneira, nas obras de Moore Jr. (1986) e de Dubet (2008), o princípio da igualdade de oportunidades ${ }^{8}$, que já se constitui numa delimitação

${ }^{8}$ É importante assinalar que as críticas ao princípio da igualdade de oportunidades têm sido objeto de estudos dos sociólogos da educação desde a década de 1960. As perspectivas mais 
da igualdade em educação, aparece como um dos compromissos das sociedades democráticas e conta com grande legitimidade. Esse princípio não supõe apenas a promoção na escala social, mas visa permitir - e possibilitar - que cada um se desenvolva plenamente. São as políticas de equidade ${ }^{9}$, no sentido atribuído por Rawls (2002), que se traduzem no imperativo da educação gratuita e universal, dos sistemas de bolsas e cotas, das modalidades de avaliação e seleção, dos veredictos escolares, da distinção dos diplomados, da hierarquização das carreiras profissionais. Estas fundamentam o dogma meritocrático de que toda expansão da escolarização é justa e eficaz, constata Duru-Bellat (2006). Nesta perspectiva, a solidariedade, que também integra os princípios da modernidade, não significa a afirmação do direito de todos à igualdade a ser promovido pela escola, mas, ao contrário, o reconhecimento da desigualdade das oportunidades e a aplicação de contrapartidas compensatórias.

No entanto, apesar da diversificação das ações voltadas à democratização do acesso e à inclusão, as desigualdades fracionam-se, multiplicam-se e diversificam-se no âmbito da escola, do mundo do trabalho, das hierarquias sociais, sem que se consiga desmontar o mecanismo e a lógica que elas ocultam. Sua persistência tem instigado novas abordagens, como se pode ver nos trabalhos de Terrail (2002), ao se perguntar se a ambição de uma escola democrática numa sociedade fortemente desigual tem sentido, ou nos estudos de Dubet (2006), quando busca compreender os sentimentos de injustiça, ou ainda na reflexão de Bihr e Pfefferkorn (2008), que procuram analisar as múltiplas dimensões das desigualdades sociais, caracterizando-as como um sistema que se articula na ordem do ter, do poder e do saber.

Esse sistema faz com que a contradição entre o princípio da igualdade de todos os alunos e a necessidade de torná-los desiguais passe despercebida, pois tudo o que coloca em xeque a compatibilidade entre esses dois fatores é enviado para fora do "santuário escolar". Vale lembrar aqui a noção de função social da educação, desenvolvida por Émile Durkheim (1858-1917), cuja influência sobre a constituição do sistema educacional brasileiro tem sido frequentemente

radicais foram apresentadas por Bourdieu (1964) e Bourdieu e Passeron (1970), tendo sido seguidas por outras, vindas de diferentes matrizes teóricas, mas todas alvejando o caráter dissimulado do discurso e das práticas educacionais.

${ }^{9}$ A distinção semântica entre equidade e igualdade se mantém, alerta-nos Garnier (2010, p. 12-13). Equidade é o produto da justa apreciação do que é devido a cada um segundo um princípio superior de justiça, mas não implica necessariamente a igualdade, no sentido em que cada um deveria receber uma parte igual, isto é, mensurável e comparável à parte recebida por outrem. Garnier distingue equidade igualitária, que é regulada a partir da igualdade frente à instrução, e equidade segregada (modelo híbrido), que também se refere a um princípio de justiça, mas supõe formas de educação diversificadas em função da origem social. 
reafirmada. Durkheim refere-se à dupla função da escola: homogeneizar, por meio da difusão de uma moral laica ${ }^{10}$, e diferenciar, por meio da preparação para o exercício de funções sociais e profissionais definidas pela sociedade.

Enfim, essa contradição, que a configuração dos sistemas de ensino apresenta como antinomias intransponíveis (democratização/seleção, quantidade/ qualidade, público/privado), persiste apesar do esforço para superar as tensões entre exigências sociais opostas ou entre os fins propostos e os meios indispensáveis para realizá-los. Mas é no quadro das discussões sobre a ideologia meritocrática que o desencantamento face às políticas educacionais se torna mais radical e que as injustiças se tornam cada vez mais evidentes e menos toleradas.

Tanto entre pesquisadores quanto entre políticos e administradores, a meritocracia constitui um dos temas mais clássicos, por referir-se a um princípio que harmoniza diferenças individuais e desigualdades sociais, promovendo o equilíbrio e a eficácia global da sociedade: todo indivíduo é estimulado a explorar ao máximo seus talentos, a ocupar o lugar que lhe conferem seus dons, sua vocação, seu esforço, sua destreza, sua qualificação, sua experiência. Sem o mérito não haveria outra maneira, senão a do nascimento (ancorada em propriedades "herdadas"), de distribuição dos indivíduos numa escala de estratificação social. Ele é considerado, portanto, como a única maneira (legítima) de produzir desigualdades justas (DUBET, 2008). Cabe assim ao Estado a prerrogativa - e o dever - de promover um amplo acordo sobre o princípio e as formas de seleção e de classificação, o que tem permitido, quase sem resistências, passar da utopia da escola para todos à escola para os melhores.

Como vimos, é o princípio do mérito que leva a reconhecer como aceitáveis as diferenças dos resultados escolares e a situar a escola, desde o final do século XIX, como a única via ao mesmo tempo justa e eficaz de repartir os lugares (desiguais) nas sociedades atuais (DURU-BELLAT, 2006). Ele vem, ao longo dos tempos, dando sentido aos movimentos de massificação do ensino, pois supõe-se que, ao conquistar a igualdade jurídica de acesso aos bens educacionais, desapareçam os obstáculos ao desenvolvimento individual. A igualdade do direito à educação exige, portanto, tratar de forma igual todas as crianças, num determinado espaço público, o da escola, que se presume protegido das desigualdades dos meios de origem, dos apelos do mercado, da influência dos particularismos e dos interesses dominantes (GARNIER, 2010). A escola figura como um oásis de justiça num mundo marcado por injustiças.

As críticas à meritocracia vêm de diferentes frentes, como sublinham Kreimer (2000) e Valle e Ruschel $(2009,2010)$; todas procuram desvelar as

${ }^{10}$ Noção amplamente desenvolvida na obra Educação moral, recentemente publicada no Brasil (DURKHEIM, 2008). 
lógicas que estão por detrás desse princípio de justiça. A escola que goza de uma autonomia relativa, lembram Duru-Bellat e Zanten (1992), e que se constitui na "ponta de lança" dessa ideologia, deve transmitir aos alunos saberes intrinsecamente legítimos, ministrados por professores intrinsecamente competentes e realizar, a partir dessa base, uma seleção intrinsecamente meritocrática. A crítica de Bourdieu (1979) sobre os projetos meritocráticos é ainda mais radical. Ele se refere a uma espécie de "racismo da inteligência", pois considera a classificação escolar como uma classificação social que já sofreu censura, como uma alquimia, uma transmutação que tende a transformar as diferenças de classe em diferenças de inteligência, de dom. Segundo Bolívar (2005), esse modelo estabelece uma verdadeira "aliança meritocrática" entre as categorias altamente dotadas de capital cultural e a profissão docente.

Sabe-se, desde o início da escolarização, que os percursos diferenciados são explicados por fatores estritamente relacionados aos talentos e dons individuais, embora se reconheça que o mérito escolar não é distribuído de maneira aleatória e que ele, frequentemente, facilita a transformação de determinantes sociais em talentos pessoais: "O mérito pode ser uma espécie de darwinismo social mascarado por algumas virtudes" (DUBET, 2009, p. 263), por essa razão ele só tem sentido numa sociedade que valoriza algumas capacidades mais que outras, não sendo nem transparente, nem neutro como vislumbravam os idealizadores do projeto republicano.

Além disso, a igualdade do direito de acesso à escola, propagada pelos estados republicanos, nunca foi suficiente para garantir a igualdade de tratamento das crianças, respeitando-se suas singularidades, sejam quais forem sua origem social, seu sexo, sua prática religiosa, como já assinalamos. As pesquisas referentes aos aspectos subjetivos das desigualdades têm demonstrado que as camadas dominantes impõem a meritocracia como esquema de interpretação e de justificação da realidade, como manifestação enganosa de um sistema de privilégios; os dominados, ao contrário, aceitam como naturais as desigualdades e assumem as responsabilidades sobre seus próprios "fracassos" (MARTUCCELLI, 2010a, 2010b; DURU-BELLAT, 2002; DUBET; MARTUCCELLI, 1996). Esse também tem sido o caso da educação escolar brasileira, e catarinense, a qual está cercada de paradoxos: ao mesmo tempo em que se comemora, desde 1988, a conquista jurídica do direito à educação para todos persistem o baixo desempenho dos alunos, o abandono precoce, a exclusão de grandes contingentes populacionais (VALLE; MIZUKI; CASTRO, 2004; SCHNEIDER, 2010), a segregação escolar no interior dos próprios sistemas de ensino (VALLE, 2010b; VALLE; RUSCHEL, 2009; KOCH, 2010), a elitização do acesso ao ensino superior público (VALLE; SATO, 2011). 
Enfim, como mostra Braz (2011, p. 52-53), ao examinar a noção de democratização da educação na obra de Pierre Bourdieu, é por meio do mal-entendido linguístico e pedagógico, instaurado na relação de comunicação entre o corpo docente e os estudantes, que a instituição escolar e, geralmente, os sistemas de ensino acabam reduzindo o ideal da democratização a uma pura igualdade formal que, na verdade, age como conceito reprodutor das desigualdades sociais.

\section{Justiça escolar: estaríamos diante de um avatar da educação escolar?}

Não é possível refazer este país, democratizá-lo, humanizá-lo, torná-lo sério, com adolescentes brincando de matar gente, ofendendo a vida, destruindo o sonho, inviabilizando o amor. Se a educação sozinha não transforma a sociedade, sem ela, tampouco, a sociedade muda. Paulo Freire (1921-1997)

Para entender a noção de justiça escolar, que pode representar um avatar das políticas para a educação, foi necessário revisitar os princípios que vêm fundando os movimentos de escolarização das sociedades modernas e orientando os projetos de democratização da educação e as reformas educacionais. Estes remetem a uma imagem idílica da escola concebida como uma instituição naturalmente integrada, que une harmoniosamente as atividades de seus membros em torno de fins universais e preconiza uma função pedagógica única que hierarquiza papéis e condutas. Todavia, essa imagem nunca refletiu a dura realidade dos sistemas de ensino, como vimos. Ao contrário, ela representa uma norma (um padrão) desejável, que permite idealizar um projeto educacional e apresentá-lo como fruto de um consenso.

Nota-se, tendo como referência as reflexões críticas sobre a igualdade e o mérito, que a noção de justiça escolar gravita em torno desses dois princípios. Trata-se, portanto, de uma noção que faz apelo à criatividade, à mudança, à mobilização, ao engajamento político e pedagógico, desafiando professores, pesquisadores e administradores da educação. Produzida a partir da combinação entre o pensamento (metafísico) de filósofos gregos, os ideais (físicos) dos iluministas e perspectivas múltiplas e complexas de autores contemporâneos, essa noção está em processo de construção. Mergulhada em incertezas 
e ambiguidades, ela vem se firmando no cruzamento de tensões diversas e de diferentes tendências, sofrendo a influência da decomposição/recomposição de vários campos do conhecimento.

Por essa razão, essa reflexão apoia-se numa relação que se revela fecunda entre a sociologia da educação - ou da escola (DURU-BELLAT; ZANTEN, 1992; DURU-BELLAT, 2002) - que abrange um campo vasto e de uma infinita variedade, a sociologia da experiência escolar (DUBET; MARTUCCELLI, 1996) que alerta para as diferentes formas e espaços de socialização, a sociologia do fracasso escolar (LAHIRE, 2000) que procura desvelar as desigualdades sociais face à escola, a sociologia do indivíduo (MARTUCCELLI, 2010a, 2010b) que leva em conta o "crescimento estrutural da singularidade" assim como o "segredo simbólico" ocultando a natureza das representações mentais (PETITAT, 1998b), a sociologia das profissões (DUBAR; TRIPIER, 1998) que analisa o espaço escolar a partir do cruzamento de múltiplas identidades, a sociologia dos saberes escolares (VALLE, 2008, 2011) que permite lançar um novo olhar sobre a reprodução cultural e a prática docente, e as sociologias da família, da juventude, da infância...

Como sabemos, a escola, à sua maneira, participa ativamente de um dos grandes ideais dos tempos modernos: avançar na direção de uma sociedade de posições conquistadas deixando para trás a sociedade de posições transmitidas e/ou herdadas ${ }^{11}$. Apesar da distância entre as intenções explícitas das políticas educacionais e a realidade dos sistemas de ensino, espera-se-em todos os lugares e em todos os momentos - que a escola assegure o triunfo dos mais capazes, dos mais esforçados. No entanto, essas políticas enfrentam a contradição entre o "desejo de igualdade" e realidades hierárquicas e desiguais. As dificuldades não se restringem ao fato de que alguns alcançam mais êxito do que outros, ou de que algumas habilitações formam a elite e outras a "massa", mas ao caráter seletivo e diferenciador dos sistemas de ensino. Foi justamente a massificação que pôs à prova essa contradição. Tendo se tornado suporte ao desenvolvimento individual e à preparação para a vida profissional, e não mais iniciação a uma ordem humana idealmente situada na universalidade da condição humana, a educação concerne indivíduos singulares, situados num espaço e num tempo, em que as aspirações e as disposições estão ligadas aos mundos sociais e culturais nos quais eles evoluem.

${ }^{11}$ Destacamos a obra do pensador brasileiro Anísio Teixeira (1971) sobre o direito à escola, pública, universal e gratuita, onde defende a tese de que "educação não é privilégio". Nesta obra, assim como no conjunto do pensamento pedagógico dos "pioneiros da educação nova", a educação escolar exerce um papel central nos projetos de construção de uma nova sociedade brasileira. 
Ora, desde os trabalhos de Bourdieu e Passeron (1964 e 1970), sabemos que a meritocracia não é um princípio que preconiza a igualdade social. Ao contrário, ela visa distinguir os mais talentosos por meio da autoridade legitimadora da escola, exercida por uma "competição meritocrática" que favorece os privilégios ligados ao nascimento, reproduzindo assim as fronteiras sociais. Fica evidente, portanto, que a situação familiar, social, cultural e profissional exerce um papel considerável sobre o rendimento escolar. A tese clássica destes autores relacionada ao lugar da escola na reprodução social ainda não foi refutada, como mostram as enquetes do Programme for International Student Assessment (PISA) ${ }^{12}$, retomadas por Baudelot e Establet (2009, p. 61), "é nos países em que a meritocracia republicana é mais fortemente reivindicada que os destinos escolares aparecem mais fortemente ligados às origens sociais e ao capital cultural das famílias".

Indiscutivelmente, a maioria desses estudos revela, de diversas formas, a persistência da face reprodutora dos nossos sistemas de ensino, assim como o fato de que "a escola republicana [francesa, mas também brasileira] pareceu por um longo tempo 'justa' no centro de uma sociedade 'injusta"” (DUBET; MARTUCCELLI, 1996, p. 36). Todavia, esses mesmos estudos demonstram que quanto menos desigual for a sociedade, melhor é sua escola, pois "uma escola não se constitui num isolado autônomo cuja eficácia depende somente do saber-fazer e do engajamento dos professores, do comportamento dos alunos, da inteligência dos programas e dos controles exercidos sobre a maneira como eles são assimilados, das taxas de enquadramento ou da modernidade dos locais" (BAUDELOT; ESTABLET, 2009, p. 74).

Diante dessas constatações, parece-nos fundamental reconhecer a extraordinária importância da escola na transformação social e não apenas na reprodução de um arbitrário cultural. Vale lembrar com Peugny (2009) a rica experiência de homens e mulheres que cresceram acima da condição de seus pais e que têm oferecido à literatura contemporânea algumas de suas mais belas páginas. É por estarmos convencidos, juntamente com Lahire (2000, p. 295), de que a escola consegue (nos limites de suas condições) reduzir as desigualdades escolares tornando-se um espaço irradiador de conhecimentos, que temos procurado aprofundar a reflexão sobre a justiça escolar. Esta noção, além de possibilitar um campo de reflexão extremamente fecundo, permite abranger múltiplas dimensões dos sistemas educacionais e estabelecer relações entre o geral e o específico. Mesmo reconhecendo que todo otimismo em relação à escola deve

${ }^{12}$ Trata-se de uma rede mundial de avaliação de desempenho escolar que se repete a cada três anos, instituída pela primeira vez em 2000, sendo coordenada pela Organização para a Cooperação e Desenvolvimento Econômico (OCDE). 
estar cercado de muita prudência, consideramos que ela pode contribuir para uma ação política consciente, afinal ela é uma - talvez a única - instituição social capaz de promover a justiça em contextos atravessados pela injustiça, pois permanece acessível à discussão, ao debate, à negociação, à participação.

Uma reflexão prospectiva sobre a escola, tal como a que se vislumbra na noção de justiça escolar, que supõe transformações não apenas nas políticas para a educação, mas também nas formas de agir dos seus agentes, não pode ignorar as contradições que envolvem uma instituição destinada, historicamente, a responder a interesses produzidos no embate - e combate - entre diferentes princípios. Vale lembrar, com Bourdieu (1989), que é preciso tomar consciência das consequências dos veredictos escolares, que fazem com que os êxitos tenham um efeito de consagração e os fracassos transformem-se em condenação; ou com Dubet (2008), ao assinalar que a meritocracia se torna intolerável quando associa o orgulho dos vitoriosos ao desprezo pelos perdedores mas, apesar disso, goza de grande legitimidade (DURU-BELLAT; TENRET, 2009); ou ainda considerar que a adesão dos indivíduos às hierarquias escolares e ao culto escolar da hierarquia se deve ao lugar que a escola lhes destina em sua própria hierarquia, de maneira que a experiência escolar se torna central na produção de sentimentos de justiça e de injustiça. Além disso, não se pode esquecer que as hierarquias escolares podem ser tão rígidas quanto as hierarquias sociais e certamente não são mais justas, mesmo parecendo mais legítimas. Nada comprova que as competências escolares sejam todas e em todos os momentos úteis à vida social, elas simplesmente podem se limitar a classificar os indivíduos, a selecionar as elites excluindo os "menos competentes", que são, em geral, os mais desfavorecidos socialmente. Não se pode deixar de assinalar, a partir dos estudos dos sociólogos da educação, que ao longo da expansão dos nossos sistemas de ensino é sua dimensão reprodutora que tem sido priorizada (VALLE; BARRICHELLO; TOMASI, 2009).

Como se pôde ver, é na convergência de diferentes perspectivas epistemológicas pautadas na crítica à escola e aos movimentos de escolarização que emerge a noção de justiça escolar. A construção de uma escola justa supõe repensar a justiça social, assim como a contribuição da escola à coesão social por meio do desenvolvimento dos valores da democracia, da tolerância, da liberdade, da civilidade e não apenas preparar o "capital humano" e criar competências úteis ao crescimento econômico (DUBET; DURU-BELLAT; VÉRÉTOUT, 2010).

Para Dubet (2011, p. 303-304), no momento em que os estados modernos entram num modelo de cidadania pós-nacional e pós-institucional, pensar uma escola justa supõe "desenhar as apostas em torno das quais se constituiriam as novas figuras de uma formação cidadã...". Isso requer uma cultura e competências comuns, o que se torna "uma questão política essencial, uma escolha política que 
não pode ser unicamente dos especialistas da pedagogia; exige a transparência dos direitos, pois a obrigação de explicitar as regras permite torná-las mais justas, uma vez que, nesse caso, elas podem ser criticadas por suas vítimas ${ }^{13}$; supõe a civilidade escolar, de maneira que os problemas de disciplina, de violência, de desvio possam ser abordados em termos democráticos, em termos de direitos e de deveres.

Enfim, é importante considerar que, para enfrentar as incertezas, as contradições e perplexidades deste início de milênio, recursos educacionais extraordinários vêm sendo mobilizados, tanto no âmbito dos países quanto no plano das políticas de globalização. Diante de um quadro de "implosões sociais espetaculares" (PETITAT, 1998a), marcado por processos de des-estandardização, quando se assiste, "após um primeiro e longo período de industrialização de massa, a um novo avatar na produção da singularidade", como nos mostra Martuccelli (2010a, p. 2), novas questões se acrescentam à agenda dos pesquisadores e velhas questões desafiam aqueles que apostam numa escola justa: Como enfrentar as desigualdades e resistir às práticas de reprodução social? Como se posicionar face à unidade da ciência e à pluralidade das culturas? Que fins deve perseguir a escola? Que saberes ensinar? Como distinguir a meritocracia escolar tal como a percebem os indivíduos da meritocracia escolar ideal? Como formar o corpo docente e preparar-se para o avanço sem precedentes da tecnologia?...

Parece evidente que uma escola justa não é uma escola perfeita que põe em prática uma única concepção de justiça. Uma escola não pode ser justa senão quando transcende a crença num ideal trans-histórico e transcultural de justiça escolar, mas quando combina princípios de justiça diferentes, procedimento este que a distancia dos julgamentos e das proposições simplistas que buscam soluções milagrosas. Certamente, devemos buscar a igualdade das oportunidades meritocráticas, sem esquecer as ambiguidades e a plasticidade que envolvem esse princípio de justiça. Mas para que esse princípio não se volte contra si mesmo, a escola justa não deve cruzar indevidamente, e deliberadamente, as diferenças, mas assegurar o melhor nível de formação ao maior número de alunos e aos mais frágeis, fazendo com que a educação escolar seja útil à coletividade e, apesar dos seus dispositivos seletivos e classificatórios, possa garantir a autonomia e a dignidade de todos. Enfim, é precisamente o paradoxo abaixo que tem inspirado e vem dando direção às pesquisas sociológicas da educação, desenvolvidas na contemporaneidade: apreender os mecanismos da escola conservadora - e reprodutora - a fim de saber em que condições a escola pode se tornar libertadora - e justa.

${ }^{13}$ Diferentemente do que vem ocorrendo nos processos educacionais democráticos e meritocráticos que fazem com que "as vítimas interiorizem os verdadeiros mecanismos de uma sociedade ‘anthropoémique', ou seja, que vomitem ou excluam” (CARPENTIER, 2010, p. 66). 


\section{REFERÊNCIAS}

ALTHUSSER, L. Ideologia e Aparelhos ideológicos de estado. Lisboa: Presença, 1970. BAUDELOT, C.; ESTABLET, R. L'élitisme républicain. L'école française à l'épreuve des comparaisons internationales. Paris: La République des Idées/Seuil, 2009.

BAUMAN, Z. Modernidade líquida. Rio de Janeiro: Jorge Zahar Ed., 2001.

BERMAN, M. Tudo que é sólido desmancha no ar. A aventura da modernidade. São Paulo: Companhia das Letras, 2007.

BIHR, A.; PFEFFERKORN, R. Le système des inégalités. Paris: La Découverte, 2008. BOLÍVAR, A. Equidad educativa y teorías de la justicia. REICE-Revista Electrónica Iberoamericana sobre Calidad, Eficacia y Cambio en Educación, v. 3, n. 2, 2005. Disponível em: <http://www.rinace.net/arts/vol3num2/art4.pdf>. Acesso em: 20/02/2007.

BOTO, C. Na Revolução Francesa, os princípios democráticos da escola pública, laica e gratuita: o relatório de Condorcet. Educação \& Sociedade, Campinas, v. 24, n. 84, set. 2003. Disponível em: <http://www.scielo.br/scielo.php?pid=S0101$-73302003000300002 \&$ script $=$ sci_arttext $>$. Acesso em: 11/09/2008.

BOURDIEU, P. La distinction. Paris: Minuit, 1979.

. La noblesse d'État; grandes écoles et esprit de corps. Paris: Minuit, 1989.

BOURDIEU, P.; PASSERON, J.-C. A reprodução; elementos para uma teoria do sistema de ensino. 2. ed. Rio de Janeiro: Francisco Alves, 1982 (Publicação original em francês, 1970).

. Les héritiers: les étudiants et la culture. Paris: Minuit, 1964.

BRAZ, A. Bourdieu et la démocratisation de l'éducation. Paris: Presse Universitaires de France, 2011.

CARPENTIER, C. As políticas educacionais face ao desafio da igualdade. In: VALLE, I. R.; SILVA, V. L. G.; DAROS, M. D. Educação escolar e justiça social. Florianópolis: UFSC/NUP, 2010. p. 49-69.

CONDORCET, J.-A. N. C. Cinco memórias sobre a instrução pública/Condorcet. São Paulo: Ed. UNESC, 2008.

DUBAR, C.; TRIPIER, P. Sociologie des professions. Paris: Armand Colin, 1998.

DUBET, F. Injustices; 1'expérience des inégalités au travail. Paris: Seuil, 2006. Le travail des sociétés. Paris: Seuil, 2009.

. Les places et les chances. Repenser la justice sociale. Paris: La République des Idées/Seuil, 2010. 
. Mutações cruzadas: a cidadania e a escola. Revista Brasileira de Educação, Rio de Janeiro: ANPEd, v. 16, n. 47, p. 289-305, maio/ago. 2011.

O que é uma escola justa? A escola das oportunidades. Trad. de: Ione Ribeiro Valle. São Paulo: Cortez, 2008 (Publicação original em francês, 2004).

DUBET, F.; DURU-BELLAT, M.; VÉRÉTOUT, A. Les sociétés et leurs écoles. Emprise du diplôme et cohésion sociale. Paris: Seuil, 2010.

DUBET, F.; MARTUCCELLI, D. À l'école. Sociologie de l'expérience scolaire. Paris: Seuil, 1996.

DURKHEIM, É. A educação moral. Petrópolis: Vozes, 2008 (Publicação original em francês, 1925).

.Educação e sociologia. 11. ed. São Paulo: Edições Melhoramentos, $1978(\mathrm{Pu}-$ blicação original em francês, 1922).

DURU-BELLAT, M. L'inflation scolaire. Les désillusions de la méritocratie. Paris: Seuil, 2006.

. Les inégalités sociales à l'école; genèse et mythes. Paris: Presses Universitaires de France, 2002.

DURU-BELLAT, M.; TENRET, É. L'emprise de la méritocratie scolaire: quelle légitimité? Revue Française de Sociologie, n. 2, v. 50, p. 229-258, 2009.

DURU-BELLAT, M.; ZANTEN, A. H. Sociologie de l'école. Paris: Armand Colin, 1992.

FISCHER, B. T. D. Professoras: Histórias e discursos de um passado presente. Pelotas: Seiva Publicações, 2005.

GARNIER, B. Figures de l'égalité. Deux siècles de rhétoriques politiques en éducation (1750-1950). Louvain-La-Neuve: Academia Bruyant, 2010.

$\mathrm{KOCH}, \mathrm{Z}$. M. Os herdeiros da exclusão: rediscutindo a reprovação de estudantes na escola pública. In: VALLE, I. R.; SILVA, V. L. G.; DAROS, M. D. Educação escolar e justiça social. Florianópolis: UFSC/NUP, 2010. p. 221-248.

KREIMER, R. História del Mérito. 2000. Disponível em: < http:// www.geocities.com/ filosofialiteratura/históriameritoexamen>. Acesso em: 07/03/2007.

LAHIRE, B. Culture écrite et inégalités scolaires. Sociologie de l'échec scolaire à l'école primaire. Lyon: Presses Universitaires, 2000.

MARTINIELLO, M. La démocratie multiculturelle. Citoyenneté, diversité, justice sociale. Paris: Presses de Sciences Po, 2011.

MARTUCCELLI, D. Grand résumé de la Société singulariste. Paris: Éditions Armand Colin, 2010a. Coll. Individu et société, SociologieS. Disponível em: $<$ http://www.sociologies.revues.org/index3344.html>. Acesso em: 25/02/2011. 
. Philosophie de l'existence et sociologie de l'individu: notes pour une confrontation critique. 2010b. SociologieS. Disponível em: $<\mathrm{http}$ ://www.sociologies.revues.org/ index3184.html>. Acesso em: 09/03/2011.

. Sociologies de la modernité. Paris: Gallimard, 1999.

MOORE Jr., B. Injustiça; as bases sociais da desobediência e da revolta. São Paulo: Brasiliense, 1987.

PETITAT, A. Éducation et implosion sociale. Revue Française de Pédagogie, n. 124, p. 5-11, Juillet-Août-Septembre 1998a.

. Secret et formes sociales. Paris: PUF, 1998b.

PEUGNY, C. Le déclassement. Paris: Bernard Grasset, 2009.

RAWLS, J. Uma teoria da justiça. 2. ed. São Paulo: Martins Fontes, 2002.

SCHNEIDER, J. A democratização do acesso ao ensino secundário pela expansão do ciclo ginasial em Santa Catarina (1946-1969). In: VALLE, I. R.; SILVA, V. L. G.; DAROS, M. D. Educação escolar e justiça social. Florianópolis: UFSC/NUP, 2010. p. 199-219.

TEIXEIRA, A. Educação não é privilégio. 3. ed. São Paulo: Cia. Editora Nacional, 1971.

TERRAIL, J.-P. De l'inégalité scolaire. Paris: La Dispute, 2002.

VALLE, I. R. Justiça na escola: Das desigualdades justas à igualdade sem adjetivos! In: VALLE, I. R.; SILVA, V. L. G.; DAROS, M. D. Educação escolar e justiça social. Florianópolis: UFSC/NUP, 2010a. p. 19-48.

. L'idéologie méritocratique comme principe fondateur des politiques éducatives au Brésil et à Santa Catarina (1930-2000). Revue Recherches \& Éducations, Société Binet-Simon Éditions, n. 3, p. 325-348, 2010 b.

. O lugar dos saberes escolares na sociologia brasileira da educação. Currículo sem Fronteiras, v. 8, p. 94-108, 2008. 2011.

. Sociologia da educação, currículo e saberes escolares. Florianópolis: EdUFSC,

VALLE, I. R.; BARRICHELLO, F. A.; TOMASI, J. Seleção meritocrática versus desigualdades sociais: Quem são os inscritos e os classificados nos vestibulares da UFSC (1998-2007)? Linhas Críticas, Brasília, v. 16, n. 31, p. 391-418, jul./dez. 2010.

VALLE, I. R.; MIZUKI, G. E. P.; CASTRO, I. M. F. Democratizar, descentralizar, municipalizar: A expansão do ensino fundamental catarinense. Cadernos de Pesquisa, Fundação Carlos Chagas, São Paulo: Autores Associados, n. 121, p. 187-212, jan./abr. 2004.

VALLE, I. R.; RUSCHEL, E. A meritocracia na política educacional brasileira (19302000). Revista Portuguesa de Educação, Porto/Portugal, Instituto de Educação e Psicologia/Universidade do Minho, v. 22, n. 1, p. 179-206, 2009. 
. Política educacional brasileira e catarinense (1934-1996): Uma inspiração meritocrática. Revista Eletrónica de Investigación y Docência, v. 3, p. 73-92, 2010.

WALZER, M. Esferas da justiça. Uma defesa do pluralismo e da igualdade. São Paulo: Martins Fontes, 2003.

Texto recebido em 26 de outubro de 2011 .

Texto aprovado em 13 de dezembro de 2012. 